\title{
Recurrence of Colonic Cancer Twice at the Site of Stapled Colorectal Anastomosis
}

\author{
Ryouhei Futami ${ }^{1,2}$, Kimiyoshi Shimanuki², Atsushi Sugiura ${ }^{2}$, Yoshikazu Tsuchiya², \\ Masahiro Kaneko², Keiichi Okawa², Sho Mineta², Yoshihiko Sugiyama³, \\ Koho Akimaru ${ }^{1}$ and Takashi Tajiri ${ }^{1}$ \\ ${ }^{1}$ Surgery for Organ Function and Biological Regulation, Graduate School of Medicine, Nippon Medical School \\ ${ }^{2}$ Department of Surgery, Aizu Central Hospital, Fukushima \\ ${ }^{3}$ Department of Pathology, Aizu Central Hospital, Fukushima
}

\begin{abstract}
Recurrence at the site of a stapled anastomosis is generally believed to result from the luminal implantation of viable cancer cells during stapling. We report a case in which colon cancer recurred twice at the site of a stapled anastomosis, despite povidone iodine (PVP-I) lavage consisting of an enema with 5\% PVP-I solution before the operation and intraoperative lavage of the rectal remnant and the descending colon with a 10\% PVP-I solution. Three months after sigmoidectomy to resect a carcinoma of the sigmoid colon, a circular anastomotic recurrence was found at the suture line after anastomosis with a stapler. However, 11 months after the subsequent resection and reanastomosis to remove the first anastomotic recurrence, another anastomotic recurrence was found. We performed abdominoperineal resection for the second recurrence at the site of the stapled anastomosis. Suture-line recurrence could not be prevented in the present case despite lavage with a PVP-I solution for prophylaxis.
\end{abstract}

(J Nippon Med Sch 2007; 74: 251-256)

Key words: anastomotic recurrence, stapled anastomosis, colorectum

\section{Introduction}

Local recurrence is a major cause of morbidity and mortality after surgery for cancer of the large bowel $^{1,2}$. While most local recurrences may be explained by inadequate resection margins ${ }^{3}$ or occult lymphatic involvements ${ }^{4}$, the intraoperative implantation of exfoliated malignant cells may be another cause ${ }^{5-7}$. Recurrence at the site of a stapled anastomosis is generally caused by luminal implantation of viable cancer cells during end-to-end anastomosis (EEA) stapling ${ }^{56}$. To prevent suture-line recurrence, intraluminal lavage with warm saline and povidone iodine (PVP-I) solution before anastomosis has been proposed ${ }^{8-12}$. We report herein a case in which colon cancer recurred twice at the site of a stapled anastomosis, despite the use of PVPI intraluminal lavage.

Correspondence to Ryouhei Futami, Department of Surgery (Divisions of Gastroenterology, General, Breast and Transplant), Nippon Medical School, 1-1-5 Sendagi, Bunkyo-ku, Tokyo 113-8603, Japan

E-mail: ryouhei@nms.ac.jp

Journal Website (http://www.nms.ac.jp/jnms/) 

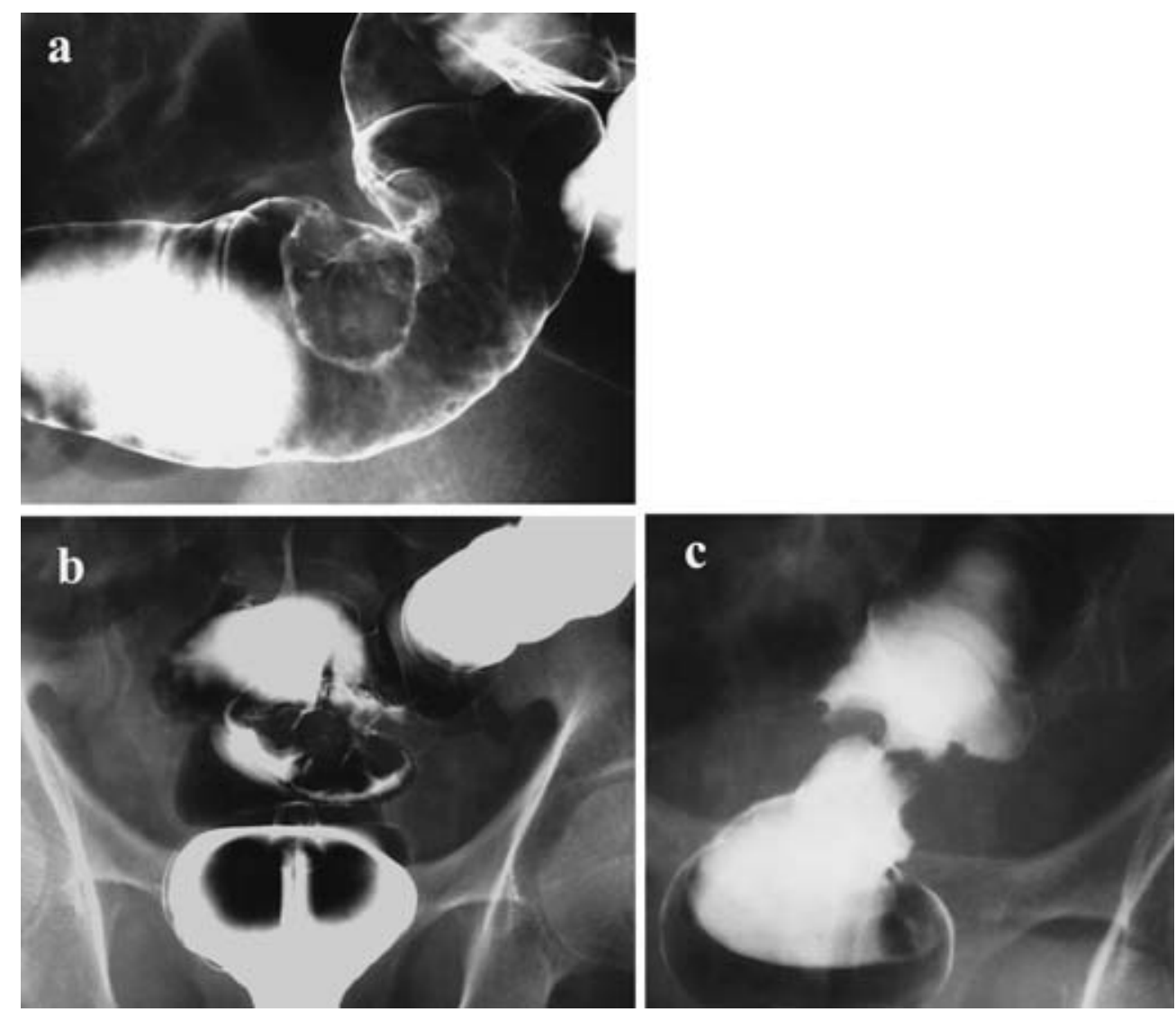

Fig. 1 Barium enema studies. a: Preoperative barium enema study. A sigmoid colon carcinoma is visible. b: Suture-line recurrence after the first operation. A side-to-end anastomosis was performed. c: Suture-line recurrence after the second operation. An EEA was performed.

\section{Case Report}

A 64-year-old man initially presented at our hospital with fecal occult blood. A double-contrast barium enema examination revealed an elevated lesion of the sigmoid colon (Fig. 1a). Colonoscopy permitted biopsy and enabled pathologic confirmation of a well-differentiated adenocarcinoma of the colon. In March 2001, sigmoid colectomy with lymph-node dissection was performed (Fig. 2a). Preoperative retrograde irrigation of the entire colon via the rectum was performed with $2,000 \mathrm{~m} l$ of a $2 \%$ PVP-I solution. During this initial operation, an EEA stapler introduced via a proximal colonic stump was used to perform a side-to-end anastomosis, after lavage of the rectal remnant with a 10\% PVP-I solution. No lymphatic invasion, vascular invasion, or regional lymph node metastasis was observed during histopathological examination of the resected specimen. Surgical margins were free from cancer cell. The cancer lesion had infiltrated the subserosal layer. After the operation, the patient did not receive any anticancer chemotherapy.

Three months after the first operation, the patient complained of bloody stool. A barium enema examination revealed a circular stenosis of the rectum (Fig. 1b). Colonoscopy subsequently showed an anastomotic stenosis with an elevated circular lesion along the suture line which was diagnosed with biopsy as a well-differentiated adenocarcinoma. A second operation was performed in November 2001. The proximal part of the rectum and segmental descending colon were resected to remove the suture-line carcinoma. Immediately before the operation, retrograde whole-colon irrigation with $2,000 \mathrm{ml}$ of $5 \%$ PVP-I solution was performed for about 15 minutes. Because the $2 \%$ PVP-I solution had been ineffective for the prophylaxis of suture-line recurrence, a 5\% PVP-I 

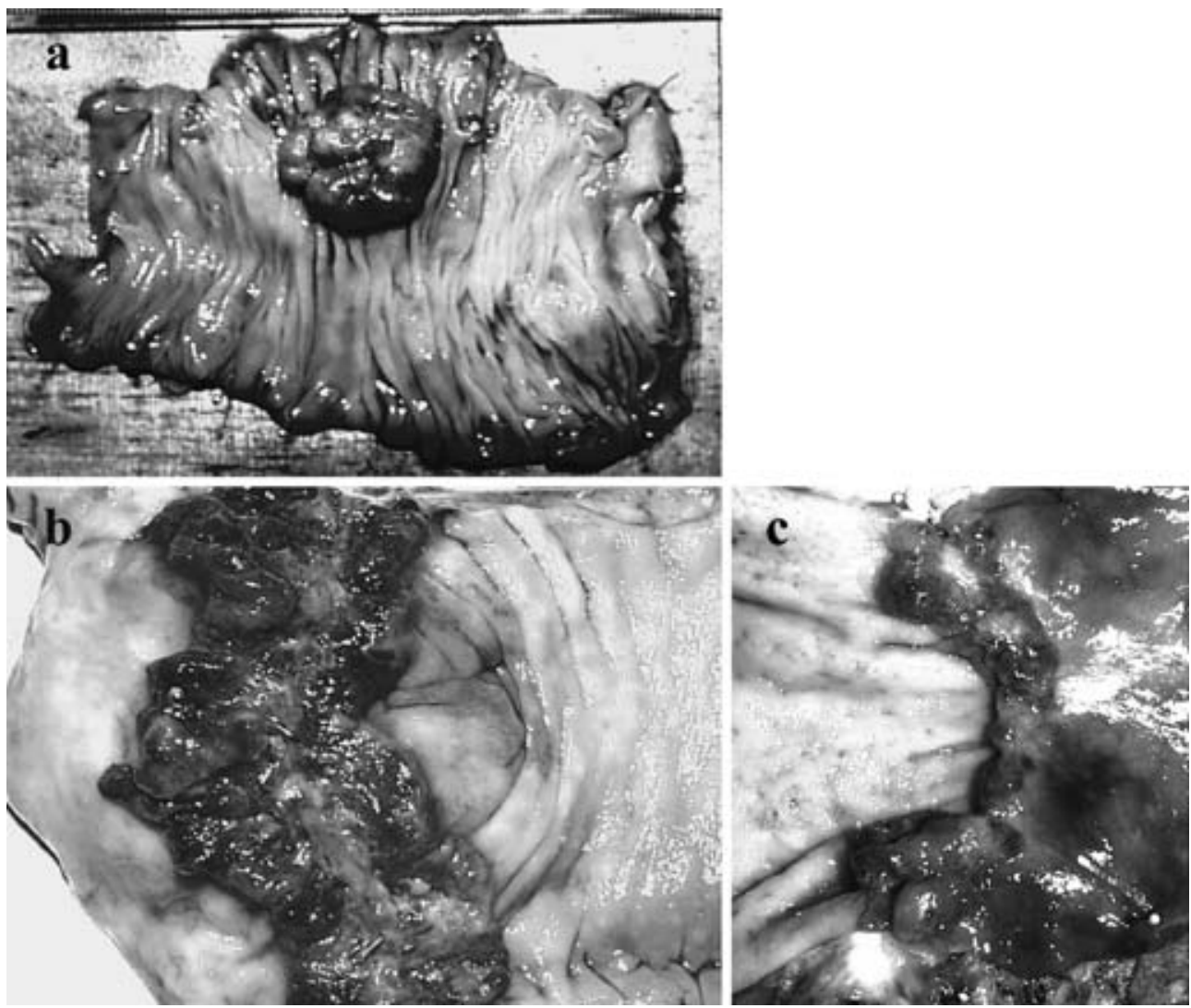

Fig. 2 Gross pathological findings of resected specimens. a: First operation. b: Second operation. c: Third operation.
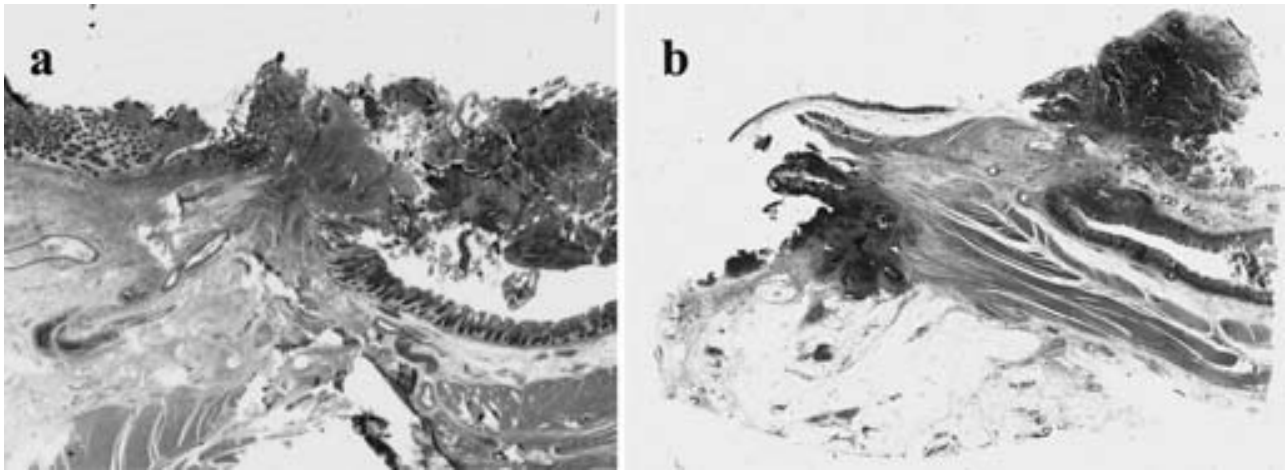

Fig. 3 Microscopic pathological findings at the suture line. a: First suture-line recurrence. b: Second suture-line recurrence.

solution was used on the basis of previously reported results ${ }^{8,13}$. A transanally introduced EEA stapler was used for EEA after lavage of the remnant rectum and the descending colon with a 10\% PVP-I solution. A cancer lesion was observed on the stapled line at the site of the stapled root (Fig. 2 b). No other lesions were noted. Histopathological examination showed a well-differentiated adenocarcinoma that had infiltrated the proper muscle layer without lymphatic invasion, vascular invasion, or lymph-node metastasis (Fig. 3a). Surgical margins were free from cancer cells.

Eleven months after the second operation, regular follow-up with colonoscopy and a barium enema examination revealed a second anastomotic stenosis with an elevated lesion (Fig. 1c). Biopsy of this lesion disclosed a well-differentiated adenocarcinoma. The serum level of carcinoembrionic antigen was $4.8 \mathrm{ng} /$ 
ml. In April 2002, abdominoperineal resection of the anastomosis and rectum was performed to remove the second recurrence at the suture line (Fig. 2c). Histopathological examination showed a welldifferentiated adenocarcinoma on the stapled line which had infiltrated the proper muscle layer without lymphatic invasion, vascular invasion, or lymph node metastasis (Fig. $\mathbf{3 b}$ ).

\section{Discussion}

Local recurrence after potentially curative colorectal cancer surgery reportedly occurs in $2.6 \%$ to $32 \%$ of patients ${ }^{14}$. Local anastomotic recurrence of colorectal cancers is usually attributable to incomplete resection ${ }^{3}$, migration of cancer cells into the lymphatics ${ }^{4}$, the presence of residual occult metastases in the mesorectum ${ }^{15}$, or the implantation of exfoliated cancer cells during anastomosis ${ }^{5-7}$. Furthermore, Law et $\mathrm{al}^{16}$. have reported that lymphovascular invasion is a major factor in local recurrence. However, in the present case, histopathological examination of all the specimens showed that surgical margins were free from cancer cell and that lymphatic invasion, vascular invasion, and lymph node metastasis had not occurred. Therefore, the implantation of exfoliated cancer cells was considered the most likely cause of local recurrence.

Malignant cells shed from the surface of a tumor can be swept along with the fecal current. Exfoliation, continued cell viability, and subsequent implantation of the tumor cells as causes of distal or suture-line recurrences have remained a controversial subject. Many authors ${ }^{17.18}$, however, have reported large numbers of exfoliated cancer cells within the intestinal lumen and have isolated desquamated viable cancer cells in lavage fluid collected before anastomosis in patients with colorectal cancer. The ability of these cells to remain viable has been demonstrated ${ }^{5}$. Exfoliated viable cancer cells have been detected in the large bowel on both the oral and anal sides of a suture line. Umpleby et $\mathrm{al}^{5}$. have reported that viable tumor cells can be detected intraluminally as far as $35 \mathrm{~cm}$ proximal to the resection margin in colorectal cancer specimens. Local recurrence can also be caused by intraoperative spillage of exfoliated viable cancer cells into the digestive lumen. Suture-line recurrences as a result of implantation mechanisms have also been suggested ${ }^{5}$. Furthermore, the possibility of cancer cells being scattered, trapped, or implanted by the operative procedure has been suggested. These exfoliated viable cancer cells might be trapped at the suture line, where they may then penetrate through the EEA stapled anastomosis. Kluger et $\mathrm{al}^{19}$. have suggested that free intraluminal cancer cells of colonic origin might penetrate through watertight anastomoses and implant on the anastomotic or peritoneal surface, where they may then initiate tumor growth. This anastomotic penetration mechanism is dependent on an intraluminal cancer cell mass. Multiple clusters of malignant cells have been observed on circular stapling devices after the completion of an anastomosis during an anterior resection for rectal cancer. In 9 of 10 cases of low anterior resection, malignant cells were identified in centrifuged saline that had been used to wash doughnuts of tissue that had been resected using an EEA stapler, even though histological examinations had shown the tissues to be tumor-free ${ }^{6}$. Malignant cells collected by a stapler can be implanted during anastomosis and can cause subsequent anastomotic recurrence. Therefore, thorough intraluminal colorectal lavage performed just before anastomosis is an important step for reducing the risk of local recurrence.

The intraluminal application of one of several tumoricidal agents has been advocated and has reported to reduce the incidence of suture-line recurrence from a range of $10 \%$ to $16 \%$ to a range of $2 \%$ to $3 \%^{9,20,21}$. These cytotoxic agents are used to prevent the implantation of viable exfoliated tumor cells responsible for local recurrence of colorectal cancer. The cytotoxic efficacy of PVP-I was tested in a rat model $^{7}$ in which intraluminal colon cancer cells derived from chemically induced colon cancer were introduced $2 \mathrm{~cm}$ proximal to a colonic anastomosis and subsequent anastomotic tumor growth was observed. The administration of PVP-I solution significantly reduced the incidence of tumor growth. Viable intraluminal tumor cells cause anastomotic 
tumor growth by becoming implanted at the site of anastomosis, but PVP-I has a cytotoxic effect on these cells. Whole-colon washout on-table using 5\% PVP-I via the appendix seems clinically feasible ${ }^{8}$. This technique deserves further study as a substitute for preoperative bowel preparation and may help prevent carcinoma recurrence caused by the implantation of viable exfoliated tumor cells. A $5 \%$ solution is recommended because 1\% PVP-I may be inactivated in vivo by organic substances ${ }^{13}$. A $5 \%$ PVP-I solution has been reported to be $100 \%$ tumoricidal in vitro and remained so after colonic irrigation $^{10}$.

In the present case, cancer cell implantation was thought to have caused the recurrence, despite the use of PVP-I lavage. Whole-colon washout with 2,000 $\mathrm{ml}$ of 5\% PVP-I for 15 minutes and intraoperative local irrigation of the rectum remnant with $10 \%$ PVP-I could not prevent suture-line recurrence. Distal implantation on intact mucosa occurs rarely, if ever, but viable exfoliated cells presumably can be trapped at an anastomotic suture or staple line during an operation. Anastomotic recurrence after the resection of colorectal carcinoma has been attributed to incomplete whole-colon washout. The frequency of lavage, the concentration of the PVP-I solution, the volume of the solution, the lavage time, the contact time, the route of irrigation, and the use of complete entire colorectal irrigation and preoperative irrigation, which are thought to be causative factors of incomplete whole colon washout, should be studied clinically.

The most appropriate concentration, volume, and contact time of PVP-I solution for reducing sutureline recurrence have been documented. An appropriate volume of irrigation solution is a quantity that enables the entire large bowel to be flushed. Complete whole-colon irrigation with tumoricidal agents should be performed. Mariani et $\mathrm{al}^{10}$. have reported that 2 minutes and approximately $1 l$ of a retrogradely infused 5\% PVP-I solution were required to reach the cecum in all their patients. Jenner et $\mathrm{al}^{11}$. have performed rectal washout with 200 to $500 \mathrm{ml}$ of normal saline via a Foley catheter inserted into the rectum. Sayfan et $\mathrm{al}^{12}$. have suggested that rectal-stump washout during anterior resection for carcinoma should be a routine procedure and that the volume of lavage fluid should be greater than $500 \mathrm{ml}$. More than $500 \mathrm{ml}$ of PVP-I solution is required to wash only the rectum, and 1,000 to $2,000 \mathrm{ml}$ is required to irrigate the entire large bowel.

More than 30 minutes of contact with a 5\% PVP-I solution produces severe damage to the colonic mucosa, leading to detachment of the epithelial cell layer in rats ${ }^{8}$. However, a solution of this concentration is considered to be effective and to have minimal adverse effects when a contact time of less than 30 minutes is used.

More than $1,000 \mathrm{ml}$ of a $5 \%$ PVP-I solution and a contact time of 10 minutes are required to wash the large bowel during preoperative preparations for colorectal cancer surgery.

Wind et $\mathrm{al}^{22}$. have suggested that recurrence may develop at scars in the anal mucosa when a staple gun has been introduced for anastomosis. Cancer cells may penetrate and migrate through the needle holes and then enter the bruised mucosa. Mucosal damage by biopsies in the presence of viable colon cancer cells resulted in mucosal implantation and intraluminal tumor growth in 1 of $30 \mathrm{rats}^{23}$. The intact colorectal mucosa is thought to act as a barrier to the spread of tumor cells, and mucosal damage to the nutrient beds may be necessary for implantation. Thus, suture lines, anal fissures, anal fistulas, hemorrhoidectomy sites, cecostomies, and other areas of mucosal injury may serve as beds for implantation and subsequent recurrence ${ }^{24}$. The needle holes and circular mucosal bruising produced by EEA stapling can cause mucosal injury at the suture line. Therefore, EEA staplers should be used with care. Although suture-line mucosal injury cannot be prevented during EEA stapling, other mucosal injuries can be avoided.

The present report discussed the prevention of exfoliated cancer cell implantation during anastomosis. The invasive and metastatic properties of cancer cells are regarded as causes of suture-line implantation; further review of this topic will be necessary in the future. 


\section{References}

1. Stipa S, Nicolanti V, Botti C, et al.: Local recurrence after curative resection for colorectal cancer: frequency, risk factors and treatment. J Surg Oncol Suppl 1991; 2: 155-160.

2. Ellis $\mathrm{H}$ : Curative and palliative surgery in advanced carcinoma of the large bowel. Br Med J 1971; 3: 291293

3. Quirk P, Durdey P, Dixon MF, Williams NS: Local recurrence of rectal adenocarcinoma due to inadequate surgical resection. Lancet 1986; 2: 996999.

4. Gricouroff G: Pathogenesis of recurrences on the suture line following surgical resection for carcinoma of the colon. Cancer 1967; 20: 673-676.

5. Umpleby HC, Fermon B, Symes MD, Williamson RCN: Viability of exfoliated colorectal carcinoma cells. Br J Surg 1984; 71: 659-663.

6. Gertsch P, Baer HU, Kraft R, Maddern GJ, Altermatt HJ: Malignant cells are collected on circular staplers. Dis Colon Rectum 1992; 35: 238-241.

7. Tsunoda A, Shibusawa M, Tsunoda Y, Kamiyama G, Yamazaki K, Kusano M: Effect of povidone-iodine on anastomotic tumor growth in an experimental model of colorectal cancer surgery. Anticancer Res 1999; 19: 1149-1152.

8. Basha G, Penninckx F, Mebis J, Filez L, Geboes K, Yap P: Local and systemic effects of intraoperative whole-colon washout with 5 per cent povidone-iodine. Br J Surg 1999; 86: 219-226.

9. Umpleby HC, Williamson RC: The efficacy of agents employed to prevent anastomotic recurrence in colorectal carcinoma. Ann R Coll Surg Engl 1984; 66: 192-194.

10. Mariani PP, van Pelt JF, Ectors N, Topal B, D'Hoore A, Penninckx F: Rectal washout with cytotoxic solution can be extended to the whole colon. $\mathrm{Br} \mathrm{J}$ Surg 2002; 89: 1540-1544.

11. Jenner DC, de Boer WB, Clarke G, Levitt MD: Rectal washout eliminates exfoliated malignant cells in the rectum in the vicinity of the anastomosis. Dis Colon Rectum 1998; 41: 1432-1434.

12. Sayfan J, Averbuch F, Koltun L, Benyamin N: Effect of rectal stump washout on the presence of free malignant cells in the rectum during anterior resection for rectal cancer. Dis Colon Rectum 2000; 43: $1710-1712$

13. Basha G, Penninckx F, Yap P: Influence of blood components and faeces on the vitro cancericidal activity of povidone-iodine. Br J Surg 1998; 85: 534537.

14. Abulafi AM, Williams NS: Local recurrence of colorectal cancer: the problem, mechanisms, management and adjuvant therapy. Br J Surg 1994; 81: 7-19.

15. Scott N, Jackson P, Al-Jaberi T, Dixon MF, Quirke P, Finan PJ: Total mesorectal excision and local recurrence: a study of tumour spread in the mesorectum distal to rectal cancer. Br J Surg 1995; 82: 1031-1033.

16. Law WL, Chu KW: Local recurrence following total mesorectal excision with double-stapling anastomosis for rectal cancers: analysis of risk factors. World J Surg 2002; 26: 1272-1276.

17. Hirai K, Kawahara H, Ashikaga K, et al.: The significance of the intraluminal lavage in the low anterior resection of the rectum with special reference to anastomotic recurrence (in Japanese). J Jpn Surg Assoc 1995; 56: 2296-2300.

18. Tsunoda A, Shibusawa M, Kamiyama G, Tanaka M, Yokoyama N, Kusano M: Viability of free malignant specimens removed because of colorectal carcinoma. Jap J Gastroenterol Surg 1996; 29: 1022-1027.

19. Kluger Y, Galili Y, Yossiphov J, Shnaper A, Goldman G, Rabau M: Model of implantation of tumor cells simulating recurrence in colonic anastomosis in mice. Dis Colon Rectum 1998; 41: 1506-1510.

20. Southwick HW, Harridge WH, Cole WH: Recurrence at the suture line following resection for carcinoma of the colon. Am J Surg 1962; 103: 86-89.

21. Gubareff N, Suntzeff V: Preliminary report on application of iodine in prevention of surgical dissemination of viable malignant cells. J Surg Res 1962; 2: 144-145.

22. Wind P, Douard R, Poupardin E, Cugnec PH: Anal implantation of exfoliated tumour cells from a rectal adenocarcinoma after colorectal stapled anastomosis. Eur J Surg 1999; 165: 905-906.

23. Hubens G, Lafullarde T, Van Marck E, Vermeulen P, Hubens A: Implantation of colon cancer cells on intact and damaged colon mucosa and serosa: an experimental study in the rat. Acta Chir Belg 1994; 94: 258-262.

24. Norgren J, Svensson JO: Anal implantation metastasis from carcinoma of the sigmoid colon and rectum-a risk when performing anterior resection with the EEA stapler? Br J Surg 1985; 72: 602.

(Received, February 26, 2007)

(Accepted, April 18, 2007) 